\title{
Viability selection creates negative heterozygosity-fitness correlations in female Black Grouse Lyrurus tetrix
}

\author{
Carl D. Soulsbury ${ }^{1,2}$ (1) $\cdot$ Christophe Lebigre ${ }^{2,3}$
}

Received: 18 February 2017/Revised: 22 May 2017/Accepted: 12 June 2017/Published online: 28 June 2017

(C) The Author(s) 2017. This article is an open access publication

\begin{abstract}
There is widespread interest in the relationship between individual genetic diversity and fitness-related traits (heterozygosity-fitness correlations; HFCs). Most studies have found weak continuous increases of fitness with increasing heterozygosity, while negative HFCs have rarely been reported. Negative HFCs are expected in cases of outbreeding depression, but outbreeding is rare in natural populations. Negative HFCs may also arise through viability selection acting on low heterozygosity individuals at an early stage producing a skew in the heterozygosity distribution. We tested this idea using survival and clutch parameters (egg mass, egg volume, chick mass, clutch size) in female Black Grouse Lyrurus tetrix and carried out simulations to determine how survival selection may impact the HFCs measured using clutch parameters. We show that survival is positively related to both individual heterozygosity and female body mass. There was a positive effect of body mass on all clutch parameters, but the
\end{abstract}

Communicated by F. Bairlein.

Electronic supplementary material The online version of this article (doi:10.1007/s10336-017-1474-3) contains supplementary material, which is available to authorized users.

Carl D. Soulsbury

csoulsbury@lincoln.ac.uk

Christophe Lebigre

christophe.lebigre@ifremer.fr

1 School of Life Sciences, University of Lincoln, Brayford Pool, Lincoln, UK

2 Department of Biological and Environmental Science, University of Jyväskylä, P.O. Box 35 (Ambiotica), 40014 Jyväskylä, Finland

3 French Research Institute for the Exploitation of the Sea, 29820 Plouzané, France selective mortality of females with both low heterozygosity and low body mass led to overrepresentation of high heterozygosity-low body mass females and hence a negative relationship between egg volume and heterozygosity. Using simulated data, we show that survival selection acting on both low body mass and low heterozygosity leads to a skew in the quality of breeding females, resulting in negative HFCs with egg volume. Our results indicate that survival selection can strongly influence the strength and direction of any HFCs that occur later in life and that only an integration of all aspects of individual reproductive investment and reproductive success can enable us to fully understand how heterozygosity can shape individual fitness.

Keywords Inbreeding - Outbreeding - Neutral loci . Selective mortality - Genetic diversity

\section{Zusammenfassung}

Selektion auf Überlebensfähigkeit führt bei weiblichen Birkhühnern Lyrurus tetrix zu negativen HFC-Werten

Es besteht ein breites Interesse an den Beziehungen zwischen der individuellen genetischen Diversität und fitnessrelevanten Merkmalen (Heterozygosität-FitnessKorrelationen; heterozygosity-fitness correlations; HFC). Die meisten Untersuchungen ergaben schwache kontinuierliche Fitnesszunahmen bei wachsender Heterozygosität, während von negativen HFC-Werten nur selten berichtet wird. Negative HFC-Werte sind in Fällen von Auszuchtdepression zu erwarten, wobei Auszucht in natürlichen Populationen nur selten vorkommt. Negative HFC-Werte können aber auch dadurch zustande kommen, dass die Selektion der Überlebensfähigkeit bei Individuen 
mit geringer Heterozygosität bereits in einem frühen Stadium greift und so eine Verschiebung in der Verteilung der Heterozygosität hervorruft, welche dann zu negativen HFC-Werten führt. Wir überprüften diese Theorie anhand von Überlebens- und Gelegeparametern (Eimasse, Eivolumen, Kükenmasse, Gelegegröße) von weiblichen Birkhühnern Lyrurus tetrix und führten Simulationen durch, um zu ermitteln, wie die Überlebensselektion die auf Grundlage der Gelegeparameter gewonnenen HFC-Werte beeinflusst. Wir zeigen, dass das Überleben in positiver Beziehung sowohl zur individuellen Heterozygosität als auch zur Körpermasse der Weibchen steht. Es gibt einen positiven Einfluss der Körpermasse auf alle Gelegeparameter; die selektive Sterblichkeit von Weibchen mit sowohl niedriger Heterozygosität als auch geringer Körpermasse führt zu einer Überrepräsentation von Weibchen mit hoher Heterozygosität und geringer Körpermasse und somit zu einer negativen Beziehung zwischen Eivolumen und Heterozygosität. Anhand von simulierten Daten zeigen wir, dass eine sowohl auf geringe Körpermasse als auch auf niedrige Heterozygosität wirkende Überlebensselektion zu einer Verschiebung in der Qualität der brütenden Weibchen führt, was negative HFCs bezüglich des Eivolumens zur Folge hat. Unsere Ergebnisse deuten darauf hin, dass die Überlebensselektion einen großen Einfluss auf Stärke und Richtung jeglicher zu einem späteren Zeitpunkt im Lebens auftretender HFCs ausüben kann und dass nur die Berücksichtigung sämtlicher Aspekte des reproduktiven Aufwandes und des Bruterfolges es uns ermöglicht $\mathrm{zu}$ verstehen, wie Heterozygosität die Fitness eines Individuums prägen kann.

\section{Introduction}

There is widespread empirical evidence that individual multilocus heterozygosity can be correlated to fitness traits (David 1998; Hansson and Westerberg 2002; Coltman and Slate 2003; Chapman et al. 2009; Szulkin et al. 2010). The impact of heterozygosity on fitness (heterozygosity-fitness correlations; HFCs) is commonly explained by inbreeding effects across the whole genome (referred to as the general effect hypothesis) or by localized effects at single loci (referred to as the local/direct effect hypotheses) (David 1998; Hansson and Westerberg 2002). HFCs are typically positive linear relationships but they are generally weak and explain a low amount of the variance in fitness (Coltman and Slate 2003; Chapman et al. 2009). Negative or non-linear HFCs reflecting quadratic relationships between heterozygosity and fitness (Marshall and Spalton
2000; Neff 2004) are considerably less common in the literature (Chapman et al. 2009 but see e.g. Olano-Marin et al. 2011a). As inbreeding depression is generally expected to explain positive HFCs, outbreeding depression is generally expected to explain negative HFCs (LeBas 2002; Chapman et al. 2009; Jourdon-Pineau et al. 2012). However, outbreeding depression is rare in wild populations (Pusey and Wolf 1996) and positive and negative HFCs may co-occur through differing local or general effects at functional or neutral loci (Olano-Marin et al. 2011a, b).

Individual fitness measures overall genetic contribution to the next generation(s) and results from an individual's ability to extract and allocate limited resources to competing functions (growth, survival, reproduction). Fitness components such as age-specific survival probabilities and reproductive success are not independent (Williams 1966), meaning that individuals' performance at each age/stage may have consequences on the subsequent ones directly (e.g. early death) and indirectly (e.g. negative correlations of reproductive success in consecutive years). Therefore, viability selection, whereby an individual's survival probability depends on a given trait's expression, may influence all measured evolutionary processes occurring in later ages/stages (Hadfield 2008; Nakagawa and Freckleton 2010; see e.g. Mojica and Kelly 2010). In studies investigating HFCs, fitness components are often considered separately with, for example, heterozygosity and shortterm survival (Bean et al. 2004; Canal et al. 2014) or heterozygosity and clutch size (Ortego et al. 2007; Wetzel et al. 2012). When more complex approaches are undertaken, the traits considered (heterozygosity and morphological traits such as body mass) typically act simultaneously on a single component of fitness such as survival (Richardson et al. 2004). But the degree to which viability selection directly or indirectly associated with individual fitness influences the strength and direction of downstream HFCs is not yet well known (Fig. 1).

We explored this idea in female Black Grouse Lyrurus tetrix, a short-lived lekking species with reproductive skew to older dominant males (Alatalo et al. 1991; Lebigre et al. 2007; Kervinen et al. 2016). In this species, males are philopatric and female-biased dispersal is effective at reducing inbreeding (Lebigre et al. 2008, 2010). However, inbreeding does occur and females have an increasing likelihood of mating with kin as they age (Soulsbury et al. 2011, 2012). Inbreeding and heterozygosity are known to be important in Black Grouse; offspring from inbred matings show reduced hatching mass (Soulsbury et al. 2011) and male reproductive success is positively related to individual heterozygosity (Höglund et al. 2002). We initially set out to explore the relationship of heterozygosity with two components of female fitness: survival, and clutch 


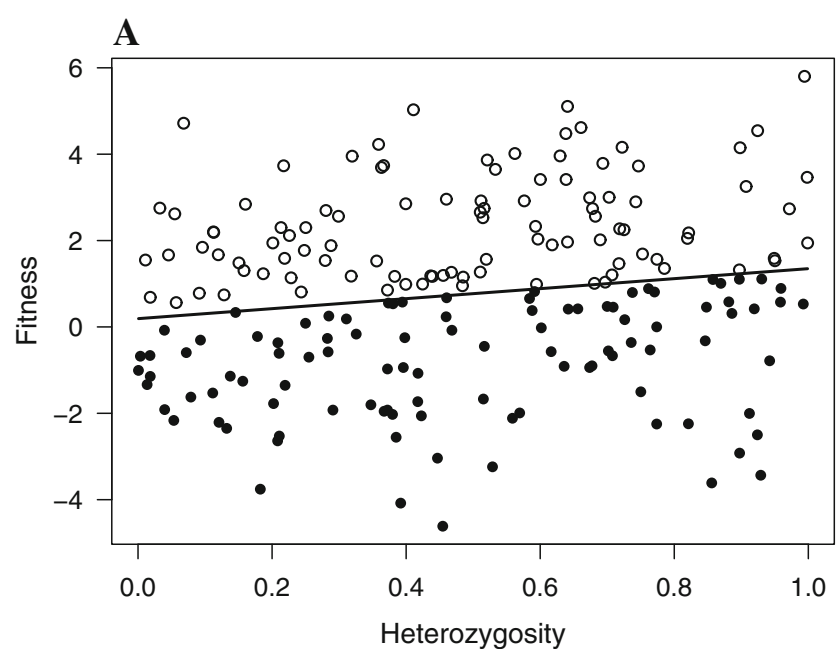

Fig. 1 Illustration of how non-random viability selection can change the direction of heterozygosity-fitness correlations (HFCs). Before selection the overall relationship is positive with both heavy (open circles) and light (filled circle) females having positive HFCs (panel

parameters (egg mass, egg volume, chick mass, clutch size). As there is little overlap between these two datasets, we generated a dummy dataset of individual heterozygosities to which we applied viability selection. We then used the resulting relationship to determine the degree to which viability selection influences the HFC measured subsequently using female clutch parameters.

\section{Materials and methods}

\section{Study sites and capture data}

We used clutch data from Black Grouse captured at from one to seven winter feeding sites in Central Finland during 2001-2006. Adults were captured using walk-in traps, ringed, and aged as yearling ( 1 year old) or older ( $\geq 2$ years old) based on colouration of the outermost primary wing feathers (Helminen 1963). Females were then weighed and several morphometric measurements taken (including wing length, tarsus length). All females were fitted with metal rings and combinations of coloured plastic rings to aid long-distance identification. A subset of females was fitted with 16- to 20-g necklace radio transmitters (approximately $1.5-2.7 \%$ of body mass) with a mortality sensor, and lifetime of 104 weeks (Holohil RI-2D); recaptured females were fitted with new transmitters.

After the mating season (end of April-early May), the nest sites of radio-tagged females were localized and the hatching date of the brood was estimated by floating the eggs in warm water (Lebigre et al. 2007). Eggs were weighed to the nearest $0.1 \mathrm{~g}$ and measured (length and

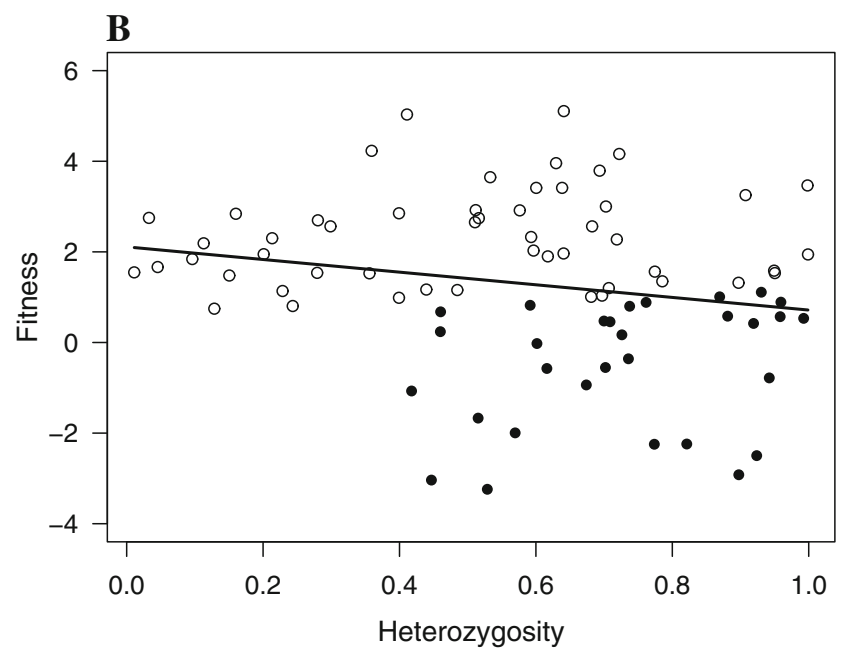

A). When viability selection removes all light females with low heterozygosity $(<0.4)$ and a random sample of all other females $(20 \%$ in this case), the overall relationship becomes negative (panel B)

width) to the nearest millimetre. Egg volume was calculated using Hoyt's formula (Hoyt 1979):

volume $=k \times$ length $\times$ breadth $^{2}$

where $k$ is a function of egg shape [in Black Grouse, $k=0.51$ (Lindén 1983)]. Egg mass is more variable than egg volume because of the effect of embryo development on the measured egg mass. Eggs that have been incubated for a longer time are lighter. Females were followed for multiple years if they survived; however, female lifespan is short (average lifespan $=1.5$ years; maximum age $=6$ ) and often we did not recapture females in another year, thus lacked further body mass measurements for them. We only used clutch data where we had a body mass measurement for that year. Females may lay a second clutch when their first nesting attempt fails early in the season (typically because of predation). These replacement clutches are fundamentally different from first clutches in terms of size/mass/sex ratio (Soulsbury et al., unpublished data) and were excluded from the datasets.

\section{Survival analysis and behavioural data}

Transmitters did not influence female survival as recapture rates of ringed females with and without transmitters were similar (Pekkola et al. 2014). Monthly female survival was monitored by searching the study areas within an approximate $5-\mathrm{km}$ radius by car and scanning the signals at elevated locations. During the incubation, a few females in more remote summer ranges or hidden by natural obstacles were located from an airplane within an approximate $10-\mathrm{km}$ radius. 
We assessed total lifespan using females of exact known age (i.e. females caught as yearlings). As yearling females may continue to disperse up until their first breeding season (Marjakangas and Kiviniemi 2005), which may lead to biases in our measures of female survival, we assessed total lifespan (weeks) of yearling females located from calendar week 24 ( $n=75$ females 5391 bird-weeks monitored) onwards from their first breeding season.

\section{Multilocus heterozygosity}

Genomic DNA was extracted from the red blood cells using reagents from the BioSprint 15 DNA Blood Kit (reference 940017; Qiagen) and a Kingfisher magnetic particle processor. All individuals were genotyped at 11 autosomal microsatellite loci (BG6, BG15, BG16, BG18, BG19, TTD2, TTD3, TTT1, TUD6, TUT3, TUT4) and one-sex linked locus (BG10) (see Lebigre et al. 2007 for details). The software package CERVUS (Kalinowski et al. 2007) provided summary statistics for the data set including heterozygosity, number of alleles per locus and $\chi^{2}$ goodness-of-fit tests for deviation from Hardy-Weinberg equilibrium (HWE). Inbreeding occurs in this population [ $\sim 13 \%$ of all clutches were produced by close relatives (Lebigre et al. 2010)]. We used standardised multilocus heterozygosity (sMLH) as a measure of female MLH; sMLH was calculated from all adult genotypes using the Rhh package (Alho et al. 2010) run in $\mathrm{R}$ version 3.2.1 ( $\mathrm{R}$ Core Team 2014). We tested whether our markers captured genome-wide heterozygosity by calculating heterozygosity-heterozygosity correlations and tested for identity disequilibrium with $g^{2}$ using the inbreedR package (Stoffel et al. 2016). However, our statistical power to capture genome-wide heterozygosity is likely to be biased by our low numbers of loci (e.g. Chapman and Sheldon 2011).

\section{Data analyses}

We first tested the relationship between female total lifespan (weeks) in relation to sMLH and female mass at first capture using linear models. This meant we had estimates for both sMLH and body mass that we could subsequently use in our dummy dataset. Using data for these females, we also correlated female mass and SMLH.

Using a separate dataset of females $(n=130-135$ females/142-147 clutches depending on clutch parameter), we then tested the relationship between sMLH and female mass on five clutch parameters (mean egg mass, mean egg volume, mean chick mass, clutch size, clutch sex ratio). Clutch parameters are often collinear, so we analysed them separately as they may show different responses to female reproductive investment. We predicted that egg size (egg mass, egg volume) and clutch size would correlate with
sMLH because previous work showed chick mass was related to pairwise relatedness of parents (Soulsbury et al. 2011). In all models, sMLH and (log-transformed) female body mass were set as fixed factors and female ring number was included as a random factor. We chose not to use female age (i.e. yearling or $\geq 2$ years old) as a cofactor because (1) female age and body mass are interdependent (yearling females are 6-7\% lighter than older females; mean individual increase in mass $\pm \mathrm{SD}=57.0 \pm 1.3 \mathrm{~g}$ ) and because body mass is more likely to directly influence female clutch parameters than age per se. Egg mass, egg volume and chick mass were analysed using the lmer function from the lme4 package (Bates et al. 2011) and lmerTest package (Kuznetsova et al. 2013). To account for the underdispersion of clutch size data (Devenish-Nelson et al. 2013), we used a generalized linear mixed-effects model using the glmmPQL function with a quasi-Poisson family from the mass package (Venables and Ripley 2002). These models used clutch size as the dependent variable, sMLH and female body mass as fixed factors, and female ring number as a random variable. Lastly, we tested whether there could be a trade-off between egg mass, volume, chick mass and clutch size using Pearson's correlations. All analyses were run in $\mathrm{R}$ version 3.2.1 (R Core Team 2014).

\section{Dummy dataset generation and analysis}

Our survival dataset and our clutch datasets are essentially separate, with very little overlap in data. To examine whether the combined effect of sMLH and mass were impacting survival, we created a dummy dataset. We used the standardised heterozygosity values of 479 females. Each individual sMLH was assigned a body mass of $740-1110 \mathrm{~g}$ at $10-\mathrm{g}$ increments which represented the lightest and heaviest female in our dataset. In total, there were 17,723 females in our dummy dataset.

Predicted lifespan was calculated using coefficients derived from the linear model of female lifespan and sMLH and body mass (see Results section). For each individual we then calculated predicted egg mass, egg volume, chick mass and clutch size based on linear mixedeffects models of clutch parameters and log female body mass only. To avoid large sample sizes impacting the results, we random resampled 1000 individuals from this initial dummy dataset. We then tested the relationship between clutch parameters, and sMLH on (1) all data, and (2) individuals predicted to survive $\geq 24$ weeks. We generated 1000 randomly sampled datasets, for which we extracted the coefficients from the model. We then compared estimates with and without viability selection using two-sample $t$-tests and tested differences in frequency distributions using a two-sample Kolmogorov-Smirnov test. 


\section{Results}

\section{Genetic profile of population}

A total of 1657 full-grown Black Grouse were genotyped leading to a total number of alleles for each locus which ranged from five to 23 (mean $=12$ alleles; Table S1). Deviations from the Hardy-Weinberg expectations were found at one locus (BG15; Table S1), and may be partly explained by the weak population subdivision observed in this study system [the Wahlund effect (Lebigre et al. 2008)] and the pooling of samples collected in different years within each lek (the presence of transgenerational close relatives might strengthen deviations from the HWE). There was a non-significant positive heterozygosityheterozygosity correlation $(r=0.01 ; 95 \% \mathrm{CI}=-0.03$ / $0.05)$. Identity disequilibrium estimated from these loci did not differ significantly from zero in the complete dataset $\left(g^{2}=0.006\right.$; bootstrap confidence interval $=-0.01-0.02$, $P=0.24)$.

\section{Heterozygosity and components of fitness}

Female lifespan was strongly positively related to both higher sMLH (linear model, estimate $\pm \mathrm{SE}=$ $80.61 \pm 26.44, t=3.05, P=0.003 ; n=75$; Fig. 2), and body mass (linear model, estimate $\pm \mathrm{SE}=230.05 \pm$ $84.92, t=2.71, P=0.008$; Fig. 2). In these females, there was a non-significant correlation between female mass and $\operatorname{sMLH}\left(r_{\mathrm{p}}=-0.16, P=0.254\right)$.

Moreover, female body mass was positively related to all clutch parameters (Table 1; Fig. 3a-c) while sMLH was only negatively related to egg volume (Table 1; Fig. 4).

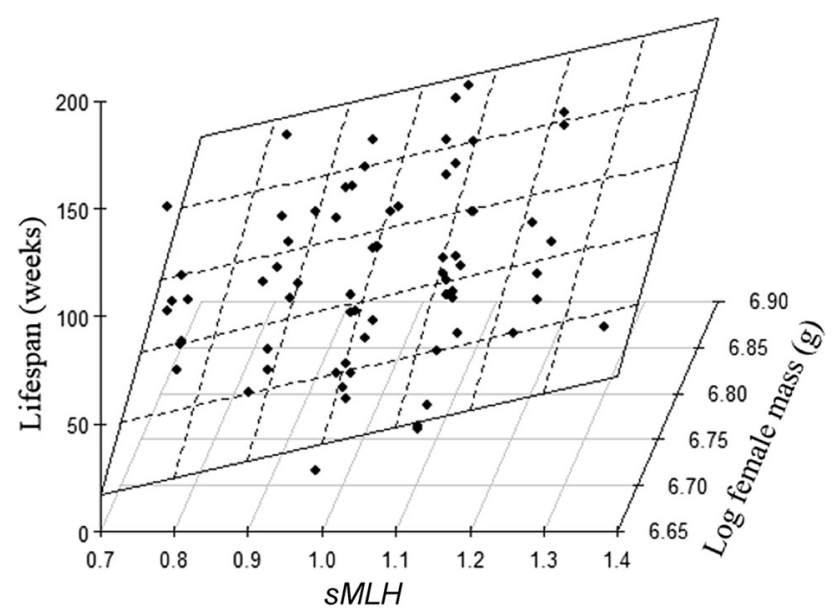

Fig. 2 Female lifespan (weeks) in relation to log body mass (g) and standardised multilocus heterozygosity $(s M L H)$. One point is a significant outlier, but its removal does not alter the relationship
There was no relationship between clutch size and mean egg mass $\left(r_{\mathrm{p}}=0.10, P=0.205\right)$, mean egg volume $\left(r_{\mathrm{p}}=-0.02, \quad P=0.836\right), \quad$ and mean chick mass $\left(\mathrm{r}_{\mathrm{p}}=-0.02, P=0.759\right)$ suggesting that the females were not trading-off investment in eggs for a greater number of eggs. Similar to the lifespan data, there was a non-significant negative relationship between female mass and sMLH (linear mixed model, estimate $\pm \mathrm{SE}=-0.01 \pm 0.03$, $t=-0.46, P=0.649$ ).

\section{Modelling linked HFCs}

Without applying the effect of survival selection, coefficients of the relationship between sMLH and clutch parameters were close to 0 but consistently positive (Table S2; Fig. 5). After applying survival selection, there was a significant reduction in all measured coefficients (all models, $\left.t_{1998}=14.41, P<0.001\right)$ which became consistently negative (Fig. 5). There was significant difference in the frequency distributions (all models, $D=0.294$, $P<0.001)$.

\section{Discussion}

\section{Heterozygosity and fitness}

Neither identity disequilibrium $\left(g^{2}\right)$ nor heterozygosityheterozygosity correlations were significantly different from zero. This is not surprising, as most reported $g^{2}$ are non-significant [mean $g^{2}=0.007$ with only 26 of 129 estimates of $g^{2}$ significantly different from zero (Miller and Coltman 2014)]. Without variance in inbreeding (i.e. when $g^{2}=0$ ) HFCs cannot arise (Szulkin et al. 2010). However, inbreeding (Lebigre et al. 2010) and inbreeding depression occur in our study population [e.g. chick mass (Soulsbury et al. 2011)]. Non-significant values of $g^{2}$ do not contradict the observation of HFC, and low levels of inbreeding are typically easier to detect through its effect on the phenotype or fitness, rather than its effect on heterozygosity. At the same time, our genotyping data are from adult birds in the population. It is likely that early viability selection (e.g. at the chick stage or prior to sampling) lowers $g^{2}$ and weakens heterozygosity-heterozygosity correlations.

Viability selection results from the differences in individual phenotypic and genetic quality leading to the selective mortality of lower quality individuals. The nonrandomness of viability selection leads to a skew in the distribution of traits of interest and may strongly influence their observed relationship with fitness (Hadfield 2008; Nakagawa and Freckleton 2010). Among phenotypic traits, body size and mass are often linked to juvenile and adult survival as, across multiple taxa, heavier and larger 
Table 1 Linear and generalised linear mixed-effect models for the relationship between clutch parameters and female standardised multilocus heterozygosity $(s M L H)$

\begin{tabular}{|c|c|c|c|c|c|c|}
\hline Model & $n_{\mathrm{f}} / n_{\mathrm{c}}$ & Parameters & Coefficient & SE & $t$ & $P$ \\
\hline \multirow[t]{3}{*}{ Egg mass } & \multirow[t]{3}{*}{$132 / 144$} & Intercept & -58.41 & 22.09 & & \\
\hline & & Log female body mass & 13.60 & 3.23 & 4.20 & $<0.001$ \\
\hline & & sMLH & -0.97 & 1.26 & 0.77 & 0.442 \\
\hline \multirow[t]{3}{*}{ Egg volume } & \multirow[t]{3}{*}{$133 / 145$} & Intercept & -4.77 & 15.84 & & \\
\hline & & Log female body mass & 5.72 & 2.33 & 2.46 & 0.015 \\
\hline & & sMLH & -2.03 & 0.93 & -2.19 & 0.030 \\
\hline \multirow[t]{3}{*}{ Chick mass } & \multirow[t]{3}{*}{$130 / 142$} & Intercept & -16.52 & 16.72 & & \\
\hline & & Log female body mass & 6.02 & 2.46 & 2.45 & 0.016 \\
\hline & & sMLH & -0.73 & 0.96 & 0.76 & 0.448 \\
\hline \multirow[t]{3}{*}{ Clutch size } & \multirow[t]{3}{*}{$135 / 147$} & Intercept & -1.89 & 1.42 & & \\
\hline & & Log female body mass & 0.58 & 0.20 & 2.78 & 0.018 \\
\hline & & sMLH & 0.11 & 0.07 & 1.39 & 0.165 \\
\hline
\end{tabular}

Number of females $\left(n_{\mathrm{f}}\right)$ and clutches $\left(n_{\mathrm{c}}\right)$ are shown for each model. Coefficient \pm SE and $t$ - and $P$-values of the models are shown individuals have higher survival rates [e.g. mammals (Milner et al. 1999); birds (Haramis et al. 1986; Monaghan and Metcalfe 1986)]. This effect is, however, often stronger in juvenile individuals than adults (Festa-Bianchet et al. 1997), though this probably depends on the life history of the species involved. Consistent with these previous findings, female Black Grouse with longer lifespans were heavier. In this species, females have relatively short lifespans, and the main source of mortality is Goshawk Accipiter gentilis predation (Angelstam 1984; Pekkola et al. 2014). Most predation occurs during the breeding season (Pekkola et al. 2014), and lighter females may have an increased need to feed during the active periods of predators leading to increased predation risk (e.g. Selås 2003; Wirsing et al. 2002). Mortality of lighter females may also occur after the breeding season if the energetic investment of rearing offspring reduces their ability to escape predation.

In addition to body mass, heterozygosity also positively influenced the survival of female Black Grouse. This is similar to the findings of many other studies where genome-wide heterozygosity and heterozygosity at specific loci have been associated with increased survival in some vertebrate species [mammals (Banks et al. 2010; Forcada and Hoffman 2014); fish (Evans et al. 2010); birds (Worley et al. 2010; Cézilly et al. 2016)]. Similar to body size, the relationship between survival and heterozygosity has been mainly found in juveniles (e.g. Bean et al. 2004; AcevedoWhitehouse et al. 2006; Cohas et al. 2009), but there is growing evidence that these effects continue throughout adulthood (Velando et al. 2015; Cézilly et al. 2016). We do not have data directly linking individual chick mortality and heterozygosity, but it is likely to be significant because of the strong relationship between inbreeding depression and chick mass (Soulsbury et al. 2011), which in itself is a major determinant of chick survival (Ludwig et al. 2010). Our data show that the effects of individual heterozygosity persist throughout adulthood and that, combined, both heterozygosity and body size determine survival in female Black Grouse.

\section{Heterozygosity, body size and reproduction}

Consistent with other studies, we found that clutch parameters were positively associated with body mass (Christians 2002). We also found a negative relationship between heterozygosity and egg volume, with weak negative trends for egg mass. While several studies have reported a positive relationship between clutch size and heterozygosity (Foerster et al. 2003; Ortego et al. 2007; Wetzel et al. 2012), few studies have examined the relationship between heterozygosity and other clutch parameters. Indeed, the only other clutch parameter examined was egg size, and some studies found a positive effect of heterozygosity (Forstmeier et al. 2012; Wetzel et al. 2012) or no effect (Ortego et al. 2007) probably because individuals trade-off egg size with clutch size (Smith et al. 1989; Nager et al. 2000). Even so, a negative relationship is unexpected. The negative HFC was weaker for egg mass, but this is not surprising since it is impacted by the timing of measurement and seems to be less responsive to female mass (see Christians 2002). The lack of any relationship between female heterozygosity and chick mass probably reflects the overriding effect of inbreeding depression acting on this trait (Soulsbury et al. 2011). 

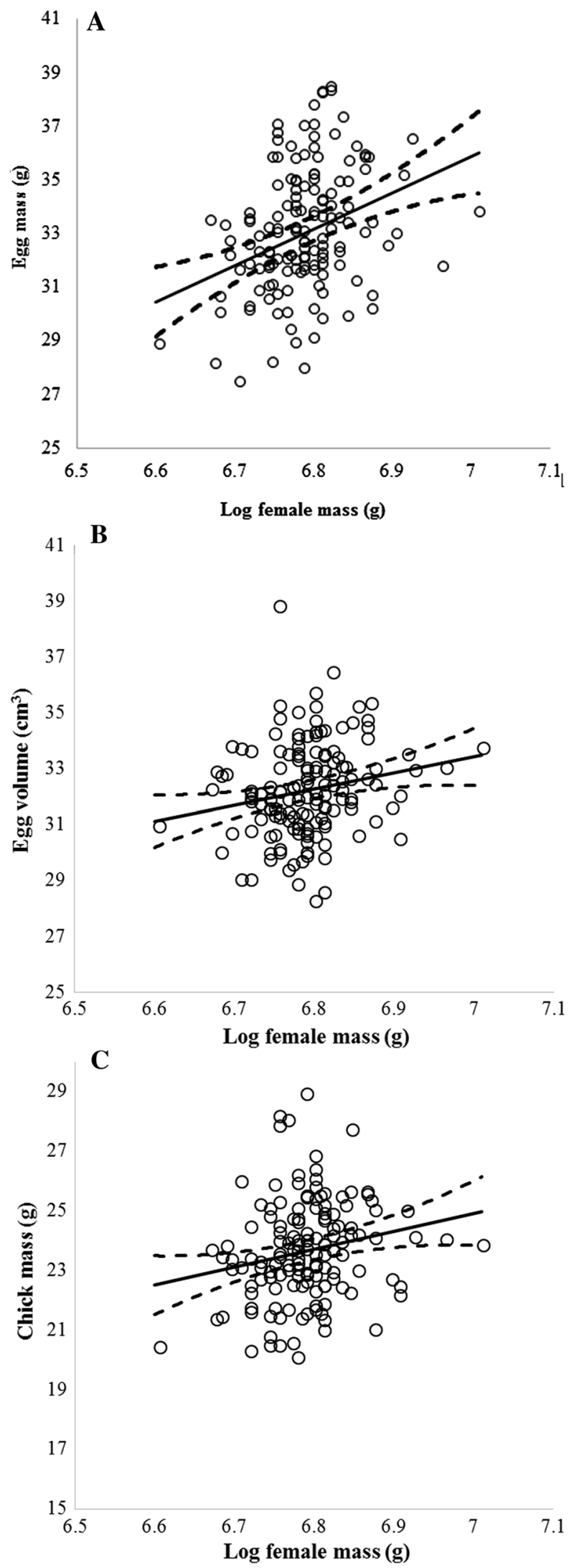

Fig. 3 Relationship between log female body mass and a egg mass $(\mathrm{g})$, b egg volume $\left(\mathrm{cm}^{3}\right)$ and $\mathbf{c}$ chick mass $(\mathrm{g})$

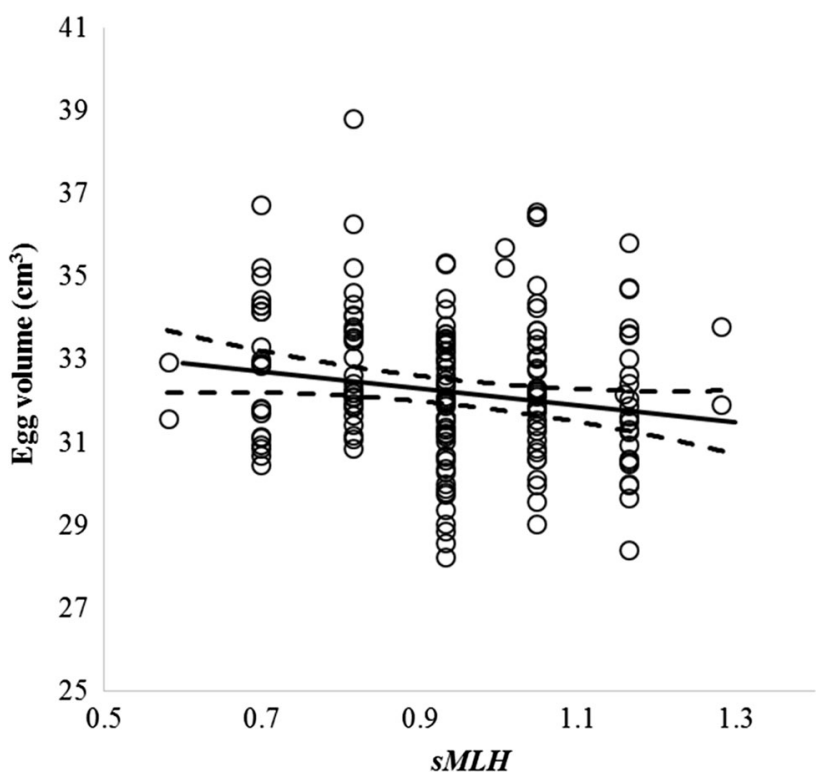

Fig. 4 Relationship between egg volume $\left(\mathrm{cm}^{3}\right)$ and standardised multilocus heterozygosity $(s M L H)$

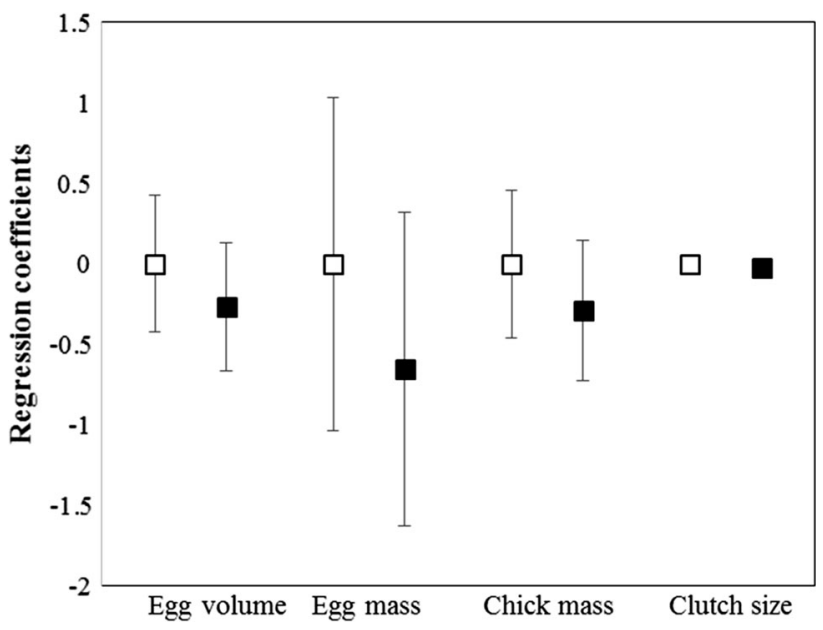

Fig. 5 Mean \pm SD regression coefficients for the relationship between clutch parameters and sMLH. Coefficients before (open square) and after (filled squares) survival selection are show. SD values for clutch size are too small to be seen on the graph

\section{Viability selection impacts HFCs}

Our empirical data show that viability selection is strongest on females with both low body mass and low sMLH. We would expect this to create a skew in the quality of breeding female in which low body mass-high sMLH females would be overrepresented leading to a negative relationship between female mass and sMLH, which could lead to negative HFC.

Our simulated data showed that applying viability selection lowered the estimated relationship between sMLH and clutch parameters, in all cases turning them 
negative. Therefore, viability selection acting at any age class is likely to impact subsequent HFCs leading to negative HFCs, as in this study, but it can also equally lead to a weakening of the already weakly positive HFCs [effect sizes $=0.05-0.10$ (Chapman et al. 2009)]. A key future direction for study would be to combine multiple agents of selection and assess how they impact HFC direction and strength.

\section{Conclusion}

Our results indicate that positive and negative HFC can cooccur for genome-wide heterozygosity measures. This is supported by a strong relationship between heterozygosity, body mass and survival. This creates variance in female quality, meaning that breeding females with low heterozygosity tend to have greater body mass. Hence, these individuals have more resources available for reproduction, which creates a negative HFC. Fitness is affected by multiple factors, and our results indicate that the effect of heterozygosity on different fitness components cannot be considered solely in isolation. Viability selection is likely to have important downstream effects on reproduction and the subsequent relationships with HFC eventually leading to negative HFCs.

Acknowledgements We thank Rauno V. Alatao, Heli Siitari, Matti Halonen, Gilbert Ludwig, Tuomo Pihlaja, Elina Virtanen and the numerous people over the years who have helped both in the lab and the field. We also thank Shinichi Nakagawa for useful comments on an early draft of this manuscript and two anonymous reviewers for helpful suggestions. Funding was provided by the Academy of Finland (grant nos. 7211271 and 7119165) and the Finnish Centre of Excellence in Evolutionary Research (Academy of Finland).

\section{Compliance with ethical standards}

Ethical approval All applicable international, national, and/or institutional guidelines for the care and use of animals were followed.

Open Access This article is distributed under the terms of the Creative Commons Attribution 4.0 International License (http://crea tivecommons.org/licenses/by/4.0/), which permits unrestricted use, distribution, and reproduction in any medium, provided you give appropriate credit to the original author(s) and the source, provide a link to the Creative Commons license, and indicate if changes were made.

\section{References}

Acevedo-Whitehouse K, Spraker TR, Lyons E, Melin SR, Gulland F, Delong RL, Amos W (2006) Contrasting effects of heterozygosity on survival and hookworm resistance in California Sea Lion pups. Mol Ecol 15:1973-1982

Alatalo RV, Höglund J, Lundberg A (1991) Lekking in the Black Grouse - a test of male viability. Nature 352:155-156
Alho JS, Välimäki K, Merilä J (2010) Rhh: an R extension for estimating multilocus heterozygosity and heterozygosityheterozygosity correlation. Mol Ecol Res 10:720-722

Angelstam P (1984) Sexual and seasonal differences in mortality of the Black Grouse Tetrao tetrix L in boreal Sweden. Ornis Scand 15:123-134

Banks SC, Dubach J, Viggers K, Lindenmayer DB (2010) Adult survival and microsatellite diversity in possums: effects of major histocompatibility complex-linked microsatellite diversity but not multilocus inbreeding estimators. Oecologia 162:359-370

Bates D, Maechler M, Bolker B (2011) lme4: linear mixedeffects models using S4 classes. R package version 0.99937542. http:// CRAN.Rproject.org/package $=$ lme 4

Bean K, Amos W, Pomeroy PP, Twiss SD, Coulson TN, Boyd IL (2004) Patterns of parental relatedness and pup survival in the Grey Seal (Halichoerus grypus). Mol Ecol 13:2365-2370

Canal D, Serrano D, Potti J (2014) Exploring heterozygosity-survival correlations in a wild songbird population: contrasting effects between juvenile and adult stages. PloS One 9: e105020

Cézilly F, Quinard A, Motreuil S, Pradel R (2016) Adult survival selection in relation to multilocus heterozygosity and body size in a tropical bird species, the Zenaida Dove Zenaida aurita. Oecologia 180:127-136

Chapman JR, Sheldon BC (2011) Heterozygosity is unrelated to adult fitness measures in a large, noninbred population of Great Tits (Parus major). J Evol Biol 24:1715-1726

Chapman JR, Nakagawa S, Coltman DW, Slate J, Sheldon BC (2009) A quantitative review of heterozygosity-fitness correlations in animal populations. Mol Ecol 18:2746-2765

Christians JK (2002) Avian egg size: variation within species and inflexibility within individuals. Biol Rev 77:126

Cohas A, Bonenfant C, Kempenaers B, Allainé D (2009) Age-specific effect of heterozygosity on survival in alpine marmots, Marmota marmota. Mol Ecol 18:1491-1503

Coltman DW, Slate J (2003) Microsatellite measures of inbreeding: a meta-analysis. Evolution 57:971-983

David P (1998) Heterozygosity-fitness correlations: new perspectives on old problems. Heredity 80:531-537

Devenish-Nelson ES, Stephens PA, Harris S, Soulsbury C, Richards SA (2013) Does litter size variation affect models of terrestrial carnivore extinction risk and management? PLoS One 8:e58060

Evans ML, Neff BD, Heath DD (2010) MHC-mediated local adaptation in reciprocally translocated Chinook Salmon. Conserv Genet 11:2333-2342

Festa-Bianchet M, Jorgenson JT, Bérubé CH, Portier C, Wishart WD (1997) Body mass and survival of Bighorn Sheep. Can J Zool 75:1372-1379

Foerster K, Delhey K, Johnsen A, Lifjeld JT, Kempenaers B (2003) Females increase offspring heterozygosity and fitness through extrapair matings. Nature 425:714-717

Forcada J, Hoffman JI (2014) Climate change selects for heterozygosity in a declining Fur Seal population. Nature 511:462-465

Forstmeier W, Schielzeth H, Mueller JC, Ellegren H, Kempenaers B (2012) Heterozygosity-fitness correlations in Zebra Finches: microsatellite markers can be better than their reputation. Mol Ecol 21:3237-3249

Hadfield JD (2008) Estimating evolutionary parameters when viability selection is operating. Proc R Soc B 275:723-734

Hansson B, Westerberg L (2002) On the correlation between heterozygosity and fitness in natural populations. Mol Ecol 11:2467-2474

Haramis GM, Nichols JD, Pollock KH, Hines JE (1986) The relationship between body mass and survival of wintering canvasbacks. Auk 103:506-514

Helminen M (1963) Composition of the Finnish populations of Capercaillie, Tetrao urogallus, and Black Grouse, Lyrurus tetrix, 
in the autumns of 1952-1961, as revealed by a study of wings. Riistatiet Julk 8:142-149

Höglund J, Piertney SB, Alatalo RV, Lindell J, Lundberg A, Rintamäki PT (2002) Inbreeding depression and male fitness in Black Grouse. Proc R Soc Lond B 269:711-715

Hoyt DF (1979) Practical methods of estimating volume and fresh weight of bird eggs. Auk 96:73-77

Jourdan-Pineau H, Folly J, Crochet PA, David P (2012) Testing the influence of family structure and outbreeding depression on heterozygosity-fitness correlations in small populations. Evolution 66:3624-3631

Kalinowski ST, Taper ML, Marshall TC (2007) Revising how the computer program CERVUS accommodates genotyping error increases success in paternity assignment. Mol Ecol 16:1099-1106

Kervinen M, Lebigre C, Soulsbury CD (2016) Simultaneous agedependent and age-independent sexual selection in the lekking Black Grouse (Lyrurus tetrix). J Anim Ecol 85:715-725

Kuznetsova A, Brockhoff PB, Christensen R (2013) lmerTest: tests for random and fixed effects for linear mixed effect models (lmer objects of lme 4 package)

LeBas NR (2002) Mate choice, genetic incompatibility, and outbreeding in the Ornate Dragon Lizard, Ctenophorus ornatus. Evolution 56:371-377

Lebigre C, Alatalo RV, Siitari H, Parri S (2007) Restrictive mating by females on Black Grouse leks. Mol Ecol 16:4380-4389

Lebigre C, Alatalo RV, Forss HE, Siitari H (2008) Low levels of relatedness on Black Grouse leks despite male philopatry. Mol Ecol 17:4512-4521

Lebigre C, Alatalo RV, Siitari H (2010) Female-biased dispersal alone can reduce the occurrence of inbreeding in Black Grouse (Tetrao tetrix). Mol Ecol 19:1929-1939

Lindén H (1983) Variations in clutch size and egg size of the Capercaillie and Black Grouse. Suomen Riista 30:44-50

Ludwig GX, Alatalo RV, Helle P, Siitari H (2010) Individual and environmental determinants of early brood survival in Black Grouse. Wild Biol 16:367-378

Marjakangas A, Kiviniemi S (2005) Dispersal and migration of female Black Grouse Tetrao tetrix in eastern central Finland. Ornis Fenn 82:107-116

Marshall TC, Spalton JA (2000) Simultaneous inbreeding and outbreeding depression in reintroduced Arabian Oryx. Anim Conserv 3:241-248

Miller JM, Coltman DW (2014) Assessment of identity disequilibrium and its relation to empirical heterozygosity fitness correlations: a meta-analysis. Mol Ecol 23:1899-1909

Milner JM, Elston DA, Albon SD (1999) Estimating the contributions of population density and climatic fluctuations to interannual variation in survival of Soay sheep. J Anim Ecol 68:1235-1247

Mojica JP, Kelly JK (2010) Viability selection prior to trait expression is an essential component of natural selection. Proc R Soc B 277:2945-2950

Monaghan P, Metcalfe NB (1986) On being the right size: natural selection and body size in the Herring Gull. Evolution 40:1096-1099

Nager RG, Monaghan P, Houston DC (2000) Within-clutch trade-offs between the number and quality of eggs: experimental manipulations in gulls. Ecology 81:1339-1350

Nakagawa S, Freckleton RP (2010) Missing inaction: the dangers of ignoring missing data. Trends Ecol Evol 23:592-596
Neff BD (2004) Stabilizing selection on genomic divergence in a wild fish population. Proc Nat Acad Sci 101:2381-2385

Olano-Marin J, Mueller JC, Kempenaers B (2011a) Heterozygosity and survival in Blue Tits (Cyanistes caeruleus): contrasting effects of presumably functional and neutral loci. Mol Ecol 20:4028-4041

Olano-Marin J, Mueller JC, Kempenaers B (2011b) Correlations between heterozygosity and reproductive success in the Blue Tit (Cyanistes caeruleus): an analysis of inbreeding and single locus effects. Evolution 20:4028-4041

Ortego J, Calabuig G, Cordero PJ, Aparicio JM (2007) Egg production and individual genetic diversity in Lesser Kestrels. Mol Ecol 16:2383-2392

Pekkola M, Alatalo R, Pöysä H, Siitari H (2014) Seasonal survival of young and adult Black Grouse females in boreal forests. Eur J Wild Res 60:477-488

Pusey A, Wolf M (1996) Inbreeding avoidance in animals. Trend Ecol Evol 11:201-206

R Core Team (2014) R: a language and environment for statistical computing. R Foundation for Statistical Computing, Vienna

Richardson DS, Komdeur J, Burke T (2004) Inbreeding in the Seychelles Warbler: environment-dependent maternal effects. Evolution 58:2037-2048

Selås V (2003) Vulnerability of Black Grouse (Tetrao tetrix) hens to Goshawk (Accipiter gentilis) predation in relation to vole cycles. J Ornith 144:186-196

Smith HG, Kallander H, Nilsson JA (1989) The trade-off between offspring number and quality in the Great Tit Parus major. J Anim Ecol 58:383-401

Soulsbury CD, Alatalo RV, Lebigre C, Rokka K, Siitari H (2011) Age-dependent inbreeding risk and offspring fitness costs in female Black Grouse. Biol Lett 7:853-855

Soulsbury CD, Alatalo RV, Lebigre C, Siitari H (2012) Restrictive mate choice criteria cause age-specific inbreeding in female Black Grouse, Tetrao tetrix. Anim Behav 83:1497-1503

Stoffel MA, Esser M, Kardos M, Humble E, Nichols H, David P, Hoffman JI (2016) inbreedR: an R package for the analysis of inbreeding based on genetic markers. Methods Ecol Evol 7:1331-1339

Szulkin M, Bierne N, David P (2010) Heterozygosity-fitness correlations: a time for reappraisal. Evolution 64:1202-1217

Velando A, Barros A, Moran P (2015) Heterozygosity-fitness correlations in a declining seabird population. Mol Ecol 24:1007-1018

Venables WN, Ripley BD (2002) Modern applied statistics with S, 4th edn. Springer, New York. ISBN 0387954570

Wetzel DP, Stewart IRK, Westneat DF (2012) Heterozygosity predicts clutch and egg size but not plasticity in a House Sparrow population with no evidence of inbreeding. Mol Ecol 21:406-420

Williams GC (1966) Natural selection, the costs of reproduction, and a refinement of Lack's principle. Am Nat 100:687-690

Wirsing AJ, Steury TD, Murray DL (2002) Relationship between body condition and vulnerability to predation in Red Squirrels and Snowshoe Hares. J Mammal 83:707-715

Worley K, Collet J, Spurgin LG, Cornwallis C, Pizzari T, Richardson DS (2010) MHC heterozygosity and survival in Red Junglefowl. Mol Ecol 19:3064-3075 